\title{
MICROPOLÍTICA ESCOLAR E ESTRATÉGIAS PARA O DESENVOLVIMENTO DO PROTAGONISMO JUVENIL
}

\author{
DAGMAR M. L. ZIBAS \\ Departamento de Pesquisas Educacionais da Fundação Carlos Chagas \\ dzibas@fcc.org.br \\ CELSO J. FERRETTI \\ Departamento de Pesquisas Educacionais da Fundação Carlos Chagas \\ e Universidade de Sorocaba \\ cferretti@fcc.org.br
}

\section{GISELA LOBO B. P. TARTUCE}

Departamento de Pesquisas Educacionais da Fundação Carlos Chagas e doutoranda do Programa de Pós-Graduação em Sociologia

da Universidade de São Paulo

gtartuce@fcc.org.br

\begin{abstract}
RESUMO
Este artigo aborda a construção do protagonismo juvenil no âmbito da reforma do ensino médio, discutindo resultados parciais de pesquisa mais ampla, os quais focalizaram cinco escolas em dois estados brasileiros. O objetivo geral da investigação foi verificar como as escolas interagiam com as diretrizes oficiais que propõem a participação efetiva de alunos e dos pais na dinâmica escolar e quais são as mediações que articulam os microprocessos institucionais às orientações políticas e sociais mais abrangentes. Este texto, no entanto, analisa apenas o espaço que o pretendido desenvo/vimento do protagonismo juvenil ocupa na trama da micropolítica escolar e, para isso, vale-se de conceitos de Stephen J. Ball como tentativa de "er" a intrincada rede de relações intramuros que ressignifica as prescrições de órgãos centrais.

ENSINO MÉDIO - REFORMA DO ENSINO - JUVENTUDE - POLITICAS PÚBLICAS
\end{abstract}

\section{ABSTRACT}

SCHOOL MICROPOLICY AND YOUTH PROTAGONISM DEVELOPMENT STRATEGIES. This article addresses the issue of the building of youth protagonism within the scope of the secondary school reform. Partial results of a broader research, focusing five schools in two 
brazilian states are discussed. The general objective of the research was to find out how schools interacted with the official guidelines stressing both students and parents to effectively take part in the school dynamics and to examine which mediations connect the institutional micro-processes to the more comprehensive political and social orientations. This text, however, focuses only the space youth protagonism occupies in school micropolicy. For that purpose, the concepts developed by Stephen J. Ball are used as an attempt to "read" the entangled network of relationships within the school, giving new meanings to what is prescribed by the central agencies.

MIDDLE EDUCATION - EDUCATIONAL REFORM - YOUTH - PUBLIC POLICIES

As Diretrizes Curriculares Nacionais para o Ensino Médio - DCNEM -, formalizadas pelo Conselho Nacional de Educação por meio da Resolução n.3 de 1998 e ainda em vigor, têm no protagonismo juvenil um de seus eixos fundamentais. Além disso, a Lei de Diretrizes e Bases de Educação - LDB - de 1996 e diversas orientações de órgãos estaduais prescreveram a abertura da gestão escolar para a participação de alunos. Essas orientações pedagógicas e gestionárias - que deslocam o estudante para o centro da cena em que tradicionalmente se situam professores e administradores - motivaram a pesquisa realizada entre 2002 e 2003, por meio da qual nos propusemos estudar o conceito de protagonismo de jovens e de pais, tal como tratado nos documentos oficiais e na bibliografia específica, bem como as práticas escolares influenciadas, por hipótese, por esses discursos'.

Este artigo pode ser considerado uma complementação de publicação anterior (Zibas, Ferretti, Tartuce, 2004a), na qual discutimos os primeiros resultados daquele trabalho, focalizando o significado do protagonismo juvenil para diferentes teóricos, assim como a proposta dos documentos oficiais da década de 90 sobre o tema. A conclusão mais importante explicitada naquele texto diz respeito ao caráter híbrido do conceito², tanto no modo pelo qual é definido por vários autores, quanto na forma em que é divulgado pelas DCNEM.

I. A pesquisa, cujos resultados parciais estão aqui discutidos, fez parte de amplo programa de investigação financiando pela Organização dos Estados Ibero-Americanos - OEl - em três países: Argentina, Espanha e Brasil, que focalizou a gestão de inovações.

2. A revisão bibliográfica que realizamos sobre o tema indica que a expressão "protagonismo juvenil" recebe diferentes interpretações, as quais contemplam outros conceitos igualmente híbridos, tais como "participação", "responsabilidade social", "identidade", "autonomia" e "cidadania". 
Além disso, verificou-se que a discussão do protagonismo juvenil na bibliografia levantada e a sua prescrição legal apontam, por um lado, para uma participação despolitizada dos jovens e para a construção de um ativismo social conformista, por outro lado, as mesmas fontes acabam indicando possibilidades para a construção da autonomia juvenil. No texto atual, analisamos os dados empíricos levantados em relação à micropolítica escolar e às estratégias institucionais concernentes ao desenvolvimento do protagonismo juvenil.

Para a realização da pesquisa e análise dos dados não nos valemos de uma concepção escolhida entre as várias detectadas na literatura, mas daquela presente nas DCNEM, que nos pareceu orientar as estratégias escolares tendo em vista o protagonismo juvenil. Tal concepção privilegia a participação de jovens no desenvolvimento das atividades voltadas para a construção de conhecimentos e valores, cabendo ao professor mais a função de orientar do que a de ensinar.

universo empírico da pesquisa abrangeu cinco escolas que ofertavam o ensino médio, sendo duas de São Paulo e três do Ceará. Dentre estas, duas (uma em São Paulo e outra no Ceará) foram escolhidas por ser consideradas, pelas respectivas Secretarias de Educação, muito bem-sucedidas na implementação da reforma do ensino médio. $O$ critério para a escolha dos outros casos (um em São Paulo e dois no Ceará) levou em conta o fato de os estabelecimentos terem algum prestígio social e/ou tradição como escolas médias. Nos termos de Stake (1999), os casos deste estudo são "instrumentais", uma vez que nosso interesse não é intrínseco a cada caso, nem tampouco intrínseco ao conjunto de casos, mas se volta para a necessidade de uma compreensão mais geral da inovação investigada. Os procedimentos usados foram pertinentes a estudos qualitativos: entrevistas semi-estruturadas e observações de variadas atividades escolares, exceto aulas.

Ao iniciarmos o estudo de caso nos cinco estabelecimentos, já compreendíamos que, em geral, as diretrizes oficiais chegam às escolas de forma diluída e fragmentada. Além disso, partimos do pressuposto de que qualquer estudo de implementação de reformas deve considerar as diferentes perspectivas, que variam conforme o lugar que cada sujeito ocupa no espaço escolar, de acordo com sua condição profissional e, ainda, de acordo com diferentes interesses pessoais ou grupais etc. A partir daí, ficou estabelecido que a focalização da micropolítica escolar seria essencial para a compreensão dos desdo- 
bramentos institucionais da reforma ${ }^{3}$. Nesse aspecto, tomamos como referência as elaborações de Ball que, ao construir uma teoria da organização escolar, define a micropolítica como o processo que liga duas facetas básicas, contraditórias e inexoráveis da vida das organizações: o conflito e o controle, este entendido aqui como a eliminação ou a prevenção do conflito. Citando Gramsci, o autor afirma que:

...(conflito e controle) não são conceitos abstratos e prescritivos, mas são conceitos significativos e reais, que tratam de explorar e explicar "o terreno [político e organizacional] em que se movem homens e mulheres". (1989, p.270-27I, tradução nossa)

A consideração desses conceitos como categorias de análise permite perceber os movimentos contraditórios da dinâmica escolar, assim descritos pelo autor:

É evidente que os processos micropolíticos atuam na organização para impedir a mudança, para manter o status quo. No entanto, a atenção aos processos micropolíticos também aclara o grau de "escassez, disfunção, fragmentação e possiblidade" que é inerente ao contexto educacional. (Ball, 1989, p.27I, tradução nossa)

O aprofundamento dessas referências teóricas possibilitou que a pesquisa, nas cinco escolas selecionadas, registrasse as convergências e divergências que ocorrem intra e intergrupos a respeito dos diversos pontos da reforma, as quais resultam e/ou evoluem para consensos, conflitos, debates, negociações, proposições ou, simplesmente, para silêncios, dissimulações, retraimentos.

Em geral, todos os membros dos grupos gestores pesquisados aderem, ao menos formalmente, às propostas dos órgãos centrais. Deve-se considerar que, num país de tradição cartorial como o Brasil, o fato de a reforma ter sido

3. No nosso caso, julgamos que, embora essencial, a abordagem da micropolítica escolar não é suficiente, sendo que a pesquisa original da qual derivou este estudo (Zibas, Ferretti, Tartuce, 2004) centrou-se em categorias que pretenderam dar conta das relações entre a micro e a macropolítica. 
instituída por legislação e o apego dos funcionários às normas e determinações legais, assim como a necessidade de se pautarem por elas, contribuem para esse processo de apropriação.

Apesar da preocupação dos diretores quanto ao cumprimento das diretrizes oficiais, pode-se dizer que nem todos os aspectos da reforma estavam visíveis nas escolas. Os mais destacados eram aqueles provenientes do âmbito estadual. Ribeiro também constatou esse fato em balanço sobre a reforma do ensino médio:

... as medidas que estão afetando mais imediatamente a organização das escolas não são as que emanam do que foi disposto explicitamente pelo Ministério ou pelo Conselho Nacional de Educação, mas as que resultam de resoluções e normas estabelecidas pelas secretarias estaduais de educação. (s.d., p. I6)

Registrou-se que, no geral, os professores dispõem de pouca informação sobre os documentos que instituem a reforma, ainda que estes tenham feito parte do processo de informação promovido pelas Secretarias Estaduais de educação e, no caso de São Paulo, da pauta de discussão de congressos e de encontros promovidos pelo sindicato, tendo sido, também, objeto de publicações deste destinadas a seus associados. No entanto, os aspectos mais conhecidos e mais veementemente debatidos pelos docentes foram os que se referiam ao seu cotidiano mais imediato e que afetavam suas condições de trabalho de forma direta. Justamente tais aspectos provinham de resoluções estaduais: as formas de avaliação e de correção de fluxo dos alunos e a distribuição de aulas na grade curricular/mudança nas grades curriculares.

Uma vez que as resoluções e normas sobre o ensino médio, emitidas no nível dos estados, são caudatárias da reforma produzida em nível nacional, "as medidas são percebidas pelos agentes escolares, sem equívoco, como parte do mesmo movimento reformista" (Ribeiro, s.d., p. 16). Entretanto, os dois tipos de diretrizes - dos governos estaduais e do governo central -, diluídos na dinâmica do cotidiano, - podem simplificar e confundir diversos conceitos, tendendo a ressignificações mais estreitas. No caso dos aspectos da reforma provenientes do âmbito nacional, constatou-se mais fortemente que os agentes escolares têm ainda pouco conhecimento sobre as Diretrizes e os Parâmetros Curriculares. Em geral, a interdisciplinaridade, o desenvolvimento de com- 
petências e a contextualização são termos vistos como vagos e imprecisos. Nesse quadro, quando se fala em protagonismo de jovens como um dos objetivos dos processos de aprendizagem, evoca-se quase sempre, nas escolas, a necessidade da formulação de "projetos". Tal associação direta e simplificadora não deixa de ter uma certa racionalidade, uma vez que a ênfase oficial na pedagogia ativa no ensino médio tem, entre outros, o seguinte pressuposto: a abertura do espaço pedagógico para as iniciativas e participação dos jovens, por meio de uma pedagogia ativa (e, portanto, de "projetos"), é um recurso importante para o desenvolvimento do protagonismo. Em vista disso, em nossa abordagem da construção do protagonismo do aluno no âmbito da micropolítica escolar, os "projetos" elaborados ou adotados pela escola tornam-se campo rico de análise.

Ainda, no espírito da reforma, a avaliação do rendimento dos alunos, definida como processual e formativa, deveria contar com a participação ativa dos jovens, uma vez que, constituindo parte integrante das estratégias de ensinoaprendizagem, deve conformar-se também com o novo princípio que deslocou a centralidade do professor para o aluno. Os conflitos gerados por essas orientações e o espaço para o desenvolvimento do protagonismo do aluno que tais processos deveriam proporcionar tornam esse um dos temas importantes desta análise.

Adicionalmente, os canais institucionalizados de participação dos estudantes, como o grêmio e o Conselho Escolar, embora não sejam "novos" na história da educação brasileira, ganharam ênfase diferenciada no discurso que envolveu a reforma curricular e de gestão e, por isso, também foram analisados para cumprimento dos objetivos da pesquisa. Sabe-se, no entanto, que esses espaços legalmente constituídos não comportam, muitas vezes, a expressão de todos os interesses dos alunos, uma vez que, inseridos na organização formal da escola, estão mais sujeitos a pressões da hierarquia institucional. Por isso, ao lado da análise desses canais, julgou-se conveniente atentar para estratégias de participação criadas espontaneamente pelos jovens como resultado de situações de diversas naturezas - conflitivas ou não - desencadeadas pelas relações informais da trama institucional.

Além disso, no estudo do protagonismo dos alunos, pareceu relevante considerar alguns aspectos do espaço físico escolar, pois se sabe que, em geral, tais espaços materializam algumas concepções sobre juventude e sobre sua 
educação, concepções que podem constituir um subtexto invisível das relações que se estabelecem na escola.

Em resumo, todas essas esferas propícias à participação dos estudantes projetos pedagógicos, avaliação do rendimento escolar, canais institucionais e organizações informais, e organização e uso do espaço físico - são constituídas por interações pessoais permeadas de conflitos, em que o controle da organização escolar é disputado, o estilo dos gestores da escola se expressa e pode ser questionado e os diferentes objetivos dos diversos sujeitos envolvidos podem se completar ou se contrapor. Neste artigo, vamos analisar como esses âmbitos organizacionais são apropriados por diferentes segmentos da unidade escolar (gestores, docentes e alunos) de maneira a confirmar ou a negar a construção do protagonismo discente.

\section{PROJETOS PEDAGÓGICOS}

Como mencionado, as escolas estudadas tendem a identificar a reforma curricular com a elaboração de "projetos". No entanto, a definição do que seja um "projeto" abrange uma gama muito variada de propostas. A seguir, tentase esgotar não somente os tipos de atividades referidas na escola como "projetos", mas também as formas de participação dos diversos agentes escolares nesses processos.

\section{Processos envolvendo gestores e docentes}

Projetos enviados por órgãos oficiais

Os órgãos oficiais tentam manter o controle sobre a gestão da reforma do ensino médio, especialmente no que se refere ao protagonismo dos alunos, enviando alguns projetos para implementação nas escolas.

Quando o projeto é de autoria de entidades oficiais (que algumas vezes têm o patrocínio de organizações internacionais), raramente é aventada a possibilidade de uma recusa explícita. Em geral, o diretor considera-se um depositário das diretrizes do órgão central, compreendendo ser sua obrigação fazer com que o projeto funcione na escola. Para isso, freqüentemente, incumbe um outro membro do grupo gestor ou um professor para coordenar as atividades, 
reservando-se o papel formal de cobrar resultados. Os projetos oficiais podem dar maior ou menor liberdade para as escolas decidirem sobre atividades pertinentes. Algumas vezes, pede-se que as escolas planejem atividades e proponham um orçamento para sua realização, de forma a obter financiamento dos órgãos centrais. Os projetos oficiais que acenam com algum financiamento são os que mais motivam as escolas a se envolverem em sua execução. No entanto, registramos diversas frustrações, quando o financiamento prometido não foi liberado.

Entretanto, muitos dos projetos oficiais não prevêem financiamento extra, devendo a escola contar com os próprios recursos para sua implementação ou inclusão, como no Ceará, no plano anual de financiamento. Nessas circunstâncias, o papel do diretor, como porta-voz do órgão central, fica mais difícil no sentido de envolver os professores em atividades que exigem mais trabaIho fora da rotina da sala de aula, sem a motivação de financiamento garantido para materiais didáticos ou outras necessidades.

Registra-se, nesse aspecto, nítida divergência de metas entre o grupo gestor - especialmente o diretor - e os docentes. $O$ primeiro está preocupado em responder as expectativas dos órgãos central e intermediário, mostrando que é gestor confiável e competente no cumprimento das diretrizes oficiais. Os professores, por sua vez, podem não se comprometer com projetos que, em geral, considerem distante de sua especialidade, muito exigentes e pouco realistas em vista das condições materiais e pedagógicas da escola. Essa disputa pelo controle do trabalho pedagógico das escolas, no entanto, nem sempre evolui para conflitos explícitos. Nos casos estudados, foi registrada, muitas vezes, certa acomodação, contentando-se o grupo gestor com um desenvolvimento apenas parcial e, freqüentemente, apenas em nível formal, dos projetos oficiais. Os processos de acomodação são decorrentes, evidentemente, de determinados estilos de gestão. De todo modo, não há recursos legais que obriguem professores a engajamento em atividades pedagógicas sugeridas por qualquer nível da administração. Assim, o grupo gestor, que efetivamente quer cumprir as determinações oficiais quanto a metodologias ou conteúdos, tem que recorrer a métodos persuasivos diversificados. No entanto, as precariedades materiais e pedagógicas da escola e o descontentamento generalizado dos docentes quanto a salários e condições de trabalho dificultam a eficácia de tais métodos. Além disso, a cultura escolar, firmemente calcada no trabalho individual e autônomo do docente, torna-se um contexto de difícil permeabilidade. 
Nesse cenário, como regra geral, as propostas enviadas à escola pelo órgão central não são incorporadas às disciplinas, mas se desenvolvem paralelamente a elas. São claramente consideradas extracurriculares, representando um adendo à programação geral. Algumas tentativas de integração acabam desenhando situações bastante artificiais, como um projeto oficial analisado, referente à formação ética e política dos alunos, cuja pretendida integração interdisciplinar consistiu, em uma das escolas, em estabelecer um dia e um horário determinados quando todos os professores - de todas as disciplinas - interromperam suas aulas para discutir o tema com os alunos, com base em um único texto, preparado por um só professor.

Adicionalmente, quando indagados especificamente sobre a implementação dos projetos sugeridos pelos órgãos oficiais, tanto o grupo gestor quanto os professores freqüentemente apontam impedimentos de dois tipos: falta de tempo para a organização do trabalho conjunto e falta de recursos materiais e didáticos. Quanto à primeira dificuldade, é necessário enfatizar que, tanto no Ceará, quanto em São Paulo, os professores trabalham, na maioria dos casos, em duas ou três escolas, o que torna rara a coincidência de horários para reuniões de grupos. Nessas circunstâncias, o fato de os docentes serem remunerados, nos dois estados, para reuniões fora de seu expediente de aulas, não garante a presença da maioria. Além disso, assuntos administrativos ou de avaliação de alunos (os chamados Conselhos de Classe) ocupam quase todo o tempo das reuniões. Assim, o planejamento anual e o projeto político-pedagógico da escola (documento oficialmente exigido) tornam-se apenas formalidades.

Essa fragilidade do trabalho coletivo na maioria das escolas estudadas é agravada pelo fato de que a função da coordenação pedagógica tem pouco prestígio junto aos docentes. Os professores, principalmente aqueles das ciências exatas, não reconhecem, freqüentemente, a competência da coordenação (geralmente exercida por profissionais formados em Pedagogia), para orientar seu trabalho ${ }^{4}$. Existe, nesse âmbito, uma situação conflituosa - latente ou explícita - a qual os coordenadores, em diversos casos, não enfrentam satisfatoria-

4. No Ceará, houve tentativa de contornar essa dificuldade com a instituição de coordenadores de área, escolhidos entre os professores. No entanto, nos casos estudados, os docentes escolhidos para a função não transitavam com facilidade da sala de aula para a coordenação do trabalho de seus pares (Zibas, 2005). 
mente. Exemplos de acomodação desses profissionais foram registrados, em casos em que se limitam a uma atuação burocrática, sem confrontar a resistência dos professores à sua orientação.

A falta de coordenação pedagógica efetiva e a conseqüente precariedade do trabalho coletivo - condições que afetam profundamente o desenvolvimento de projetos interdisciplinares - acontecem sob variados estilos de gestão e em decorrência de diferentes histórias institucionais. Por exemplo, foi registrado que um corpo diretivo coeso, há muito estabelecido, com redes de relacionamento consolidadas durante muitos anos, tende a acomodar interesses e evitar confrontos explícitos, desistindo com facilidade do controle da ação pedagógica dos professores, inclusive da implementação de projetos. As prerrogativas do grupo gestor não são abertamente questionadas, mas este também não interfere decisivamente no trabalho dos docentes, principalmente dos mais antigos. Nessa situação, diversos professores louvaram sua "autonomia", inclusive comparando a "liberdade" de que gozam na escola pública e o controle a que são submetidos nas escolas privadas em que também trabalham.

Um outro estilo de gestão e uma bem diferente história institucional também resultam em coordenação pedagógica frágil e ausência de trabalho coletivo, com prejuízo para o desenvolvimento de projetos interdisciplinares. Neste caso, ao contrário do exemplo dado, o diretor é novo na função e na escola, e esta também foi estabelecida há poucos anos. Todavia, o grupo gestor é fraturado por disputas diversas. Os conflitos são nitidamente seqüelas da última eleição para o cargo de direção, sistemática essa que é relativamente recente no sistema educacional cearense e foi instituída com o propósito de moralizar a tradicional nomeação de protegidos de políticos regionais.

No entanto, os novos procedimentos também trazem um grande enredamento político, seja em processos internos de competição entre diversos professores pretendentes ao cargo, seja por ingerência de políticos locais. Registrou-se que o processo eleitoral para o cargo de diretor pode acarretar grande divisão dentro do grupo gestor ou entre este e os professores, com inevitáveis reflexos sobre o trabalho docente e sobre os alunos, enfraquecendo o projeto pedagógico da escola

Nos dois casos, o controle por meio de projetos, que o órgão central tenta exercer sobre a gestão da reforma do ensino médio, especificamente 
sobre a inovação que se refere ao protagonismo dos alunos, perde-se nas escolas e não abala a tradicional centralização do processo ensino-aprendizagem na figura do docente. Na verdade, os projetos sofrem uma releitura, principalmente por parte dos professores, que avaliam rapidamente as possibilidades de sucesso, os ganhos e perdas em diversos níveis (profissional, pedagógico, pessoal, econômico). A partir daí, pode haver uma recusa, um envolvimento apenas parcial ou formal, ou adesão. $\bigcirc$ registrado com mais freqüência foi o envolvimento apenas parcial de alguns docentes e de pequena parte dos alunos.

A impossibilidade manifesta pelo Estado de controlar a inovação nas escolas é reforçada porque ele não cumpre adequadamente a parte que the cabe quanto ao financiamento da reforma. Ou seja, há uma contradição básica entre os objetivos da reforma e as condições oferecidas para sua implantação. $\bigcirc$ seguinte texto de Pérez Gomez e Gimeno Sacristán (apud Heras Montoya) traz um diagnóstico acurado dessa situação, embora, no caso brasileiro, não se trate apenas das carências das escolas.

...um ensino que não seja livresco e baseado em decoração necessita apoiar-se em diversos tipos de experiência. Essa experiência pode-se obter, [...] de forma vicária e pelo uso de materiais didáticos escritos, mas precisa, em muitos casos, da observação direta de fenômenos... Esses princípios [de renovação do ensino de ciências] exigem a dotação, nas escolas, de laboratórios ou de espaços equivalentes com um material mínimo e simples, para facilitar as experiências correspondentes... A necessidade de introduzir destrezas manuais, de manipulação, de observação etc... nos leva a pensar na necessidade de incrementar esses recursos didáticos nas escolas... Sem essas dotações a formulação de objetivos... [de aprendizagem significativa] fica esvaziada de conteúdo real. (1997, p.85, tradução nossa)

Na realidade, tanto as dificuldades técnicas da coordenação pedagógica quanto as restrições materiais presentes no sistema explicam apenas em parte a resistência ao trabalho coletivo. Sabe-se que a cultura profissional é historicamente avessa à abertura da "caixa-preta" das aulas para o escrutínio dos pares ou de agentes externos. Essa característica do trabalho docente foi integralmente desconsiderada nas estratégias de adoção da reforma, pretendendo-se 
que a simples prescrição legal da interdisciplinaridade desmontasse a tradição da atuação individualizada do professor.

Outra contradição da ação do Estado no esforço de gerir a reforma curricular está no fato de que não há um programa consistente e permanente de formação em serviço. Os cursos oferecidos pelo órgão central cearense são esporádicos ${ }^{5}$. No Ceará, a escola tem alguma liberdade (limitada pelos poucos recursos financeiros disponíveis), para contratar diretamente de empresas privadas, os serviços de assessoria que achar conveniente. Como não há avaliação por parte do órgão central da qualidade dessas empresas, o Estado fica sem controle de um aspecto essencial para a implantação das inovações que planeja (Zibas, 2005).

Em São Paulo, o objetivo de controle da implantação da reforma materializou-se em um grande esforço inicial para formação em serviço dos professores, em um programa que, no entanto, foi logo interrompido. Uma das dificuldades para o trabalho de formação era a grande mobilidade dos docentes nas escolas do estado, tendo havido transferências e remoções durante o ano letivo.

Observou-se entretanto que, quando a história da escola foi capaz de construir uma identidade mais sólida, os projetos oficiais foram percebidos como oportunidades de reafirmação dessa identidade, principalmente no que diz respeito à imagem de uma escola diferenciada, onde "coisas boas acontecem". Essa identidade, em geral, é construída em torno de uma liderança marcante na gestão ou de um grupo de professores muito atuantes. Essas características do corpo gestionário e docente tendem, por sua vez, a ser percebidas e destacadas de diversas formas pelos órgãos centrais e intermediários. Tanto em São Paulo quanto no Ceará, essas unidades escolares acabaram se tornando "vitrines" das respectivas Secretarias de Educação. Obtiveram, por conseqüência, melhor acolhida às suas reivindicações, o que levou a um círculo "virtuoso-vicioso" de acumulação de prestígio e de recursos.

Em resumo, pode-se dizer que os processos de adesão aos projetos pedagógicos propostos pelos órgãos centrais têm as seguintes características:

5. $\bigcirc$ Estado do Ceará tem investido na formação em nível superior de docentes que estão no magistério sem esse nível de titulação. No entanto, não havia programas sistemáticos de formação continuada no período em que foi realizado o estudo. 
- o dinamismo dos projetos que tem por base o trabalho coletivo mantém-se graças a um catalisador das atividades, geralmente o titular do grupo gestor, que apresenta características de liderança muito marcantes;

- o afastamento desse líder ameaça a continuidade dos projetos;

- os projetos oficiais podem ser transformados em projetos da escola e, como tais, desdobrados em várias outras iniciativas, mas, em qualquer caso, raramente são considerados pelos atores envolvidos como parte integrante do currículo, desenvolvendo-se paralelamente a ele;

- são poucos os professores que participam efetivamente;

- a falta de resultados mais visíveis quanto à qualidade do ensino e quanto ao envolvimento dos alunos pode diminuir, ao longo do tempo, o entusiasmo inicial dos docentes pelos projetos.

\section{Projetos com origem em outras entidades}

Em geral, ao contrário do que acontece com as propostas oficiais, os projetos, oferecidos por entidades como ONGs, universidades e empresas, tendem a ser bem acolhidos, porque, nesses casos, as escolas têm a liberdade de envolver-se com eles ou não. Outro motivo para essa diferença diz respeito ao fato de que, muitas vezes, tais organizações aportam algum recurso à escola, o que mais raramente acontece com os projetos oficiais. Tais recursos podem constituir algum material didático mais interessante, um prêmio a ser disputado com outras escolas ou subsídios didáticos para atividades que facilitam o trabalho docente e motivam alunos. Em alguns casos, o projeto externo pode ser adotado por professores como atividade regular da sala de aula. São, no entanto, em geral, eventos de curta duração e que não se integram necessariamente ao planejamento regular dos docentes, podendo constituir um interregno mais desafiador em meio a atividades rotineiras.

Outras vezes, a escola recebe projetos sem ter que se responsabilizar diretamente por seu desenvolvimento. Esses são casos em que se estabelece uma vinculação direta entre o patrocinador externo e os alunos, cedendo a escola apenas o espaço para as reuniões. Exemplos registrados: mini-cursos ministrados por alunos de universidade, cursos de empreendedorismo juvenil, oferecidos por entidade patronal, ou cursos sobre ética e direitos humanos, patrocinados por ONG. 
Assim, mesmo quando não há qualquer aporte material, o fato de receber convite para parcerias com organizações da sociedade civil (e não sofrer imposição do órgão central) parece significar ponto favorável para o status da instituição. Todos os grupos gestores contatados mencionaram com certo orgulho o fato de a escola ter sido procurada por este ou aquele agente externo com proposta de alguma colaboração para desenvolvimento de projetos. Ou seja, projetos criados fora da escola, que podem trazer alguns recursos e, ao mesmo tempo, não exigir grande criatividade docente, ou propostas que não trazem recursos, mas também não prevêem qualquer envolvimento dos professores ou dos gestores, pareceram vir ao encontro da necessidade de a escola divulgar, para os pais e para os órgãos centrais, atividades diferenciadas. Isto é, esses projetos podem preencher a lacuna representada pela ausência de controle ou de coordenação do trabalho docente. Em outras palavras, impossibilitados de articular um trabalho coletivo que evidencie que a reforma curricular do ensino médio está em andamento, alguns gestores - ao aderirem a projetos externos - podem demonstrar aos órgãos centrais e aos pais estar, pelo menos, promovendo atividades não rotineiras.

Os professores entrevistados também tendiam a aderir aos projetos que oferecessem recursos didáticos extras ou prêmios por participação ou sugerissem atividades para motivar alunos sobre conteúdos de suas disciplinas. Um projeto, patrocinado por empresa que, doando alguns livros para a escola, propunha leitura dessas obras com sugestão de atividades de compreensão de texto, foi bastante elogiado por professores da área. A adesão, sem qualquer crítica ou reflexão, a um receituário apresentado por agente externo parece indicar uma fragilidade na formação desses profissionais, mas também aponta a precariedade de recursos didáticos disponíveis na escola, onde a oferta de qualquer material um pouco mais estimulante é sempre bem-vinda.

No contexto das propostas de origem externa à escola e não vinculadas a órgãos oficiais, não se registraram, na maioria dos casos, tais conflitos e divergências de objetivos. Em diferentes instituições, com variadas dinâmicas de gestão, observou-se o mesmo consenso entre professores e grupo gestor a respeito dos benefícios que as propostas de parceria com agentes externos trazem para a escola. Nesses casos, forma-se na instituição um espaço sem disputa entre grupo gestor e professores pelo controle do trabalho docente, uma vez que este fica vinculado a um condicionante externo. 
De outra parte, quando a escola já é bastante diferenciada quanto ao seu projeto político-pedagógico, a tendência é que seja mais assediada por entidades externas e que também procure participar de concursos envolvendo projetos, de modo a manter seu perfil destacado na rede. Parece repetir-se aqui o conhecido fenômeno referente a equipes com maior trânsito político, meIhor acesso a informações e preparação técnica acima da média que conseguem sempre maiores recursos, em um círculo acumulativo do qual ficam excluídas as equipes menos preparadas, alocadas nas escolas mais carentes.

\section{Processos envolvendo alunos}

\section{Projetos de órgãos oficiais e de outras entidades}

Os alunos entrevistados, ao contrário dos professores e gestores, não estabeleceram uma diferença inicial entre projetos com origem em órgãos centrais e aqueles oferecidos por ONGs, universidades e outras entidades. A reação dos jovens a esses dois tipos de proposta é variada, no entanto, tendem a interessar-se por aquelas que quebram a rotina das aulas de "quadro negro e giz" ou pelas percebidas como capazes de lhes trazer algum benefício imediato.

A segmentação do alunado entre os que continuarão estudos em nível superior e aqueles que não pretendem fazê-lo, geralmente por impedimentos econômicos e/ou de condições de trabalho, pode gerar, em relação aos projetos, uma situação reveladora das debilidades da reforma. Os candidatos à universidade, interessados em conteúdos que sejam úteis para os exames de admissão, podem se recusar a participar dos projetos, considerando-os dispersivos ou inúteis aos seus objetivos e preferindo, nesses casos, as aulas tradicionais. Essa posição põe a nu algumas contradições da reforma. Em primeiro lugar, mostra que a intenção de retirar do ensino médio sua característica propedêutica enfrenta um dado muito concreto: a aspiração de alunos a ascenderem à universidade. Em segundo lugar, mostra a distância entre a formulação e execução dos projetos e o currículo do ensino médio. Considerados atividades "extracurriculares" e desenvolvidos como tais, os projetos tendem, realmente, a ser definidos como espaços dispersivos em relação aos objetivos escolares. 
Cursos extras, ou projetos especiais, ministrados ou coordenados por outros agentes, que não os professores da escola, costumam ser mais motivadores, provavelmente por acenarem com a possibilidade de os alunos conhecerem perspectivas diferentes. Foi esse o caso de um projeto sobre saúde, coordenado em uma das escolas por médico jovem e entusiasta, que formou multiplicadores. Nessa experiência, os jovens se apropriaram do espaço oferecido e construíram um tipo de protagonismo que tende a se ampliar - pelo menos quanto ao tema específico da saúde - mesmo depois de terminado o projeto gerador.

Essa permanência da proposta, para além da presença dos coordenadores externos, constitui uma exceção. Em geral, as iniciativas de origem externa, oficiais ou não, dificilmente se integram ao projeto escolar, correndo paralelamente ao planejamento docente. Conseqüentemente, uma vez encerradas, não costumam deixar marcas na instituição, constituindo apenas uma pausa na rotina cotidiana. Essa foi a regra mais geral, inclusive para projetos premiados internacionalmente, como no caso de uma escola cearense.

Embora os jovens mostrem especial interesse em conhecer propostas trazidas por interlocutores externos à escola, tendem também a se envolver nos projetos a respeito dos quais seus professores revelam genuíno entusiasmo e empenho.

Ao mesmo tempo, vários projetos partem de suposições falsas a respeito das características juvenis, criando situações artificiais que esvaziam as iniciativas. Foi o caso de uma proposta de oficina (centro de participação), que escoIheu um tipo de música jovem para motivar os alunos. No entanto, para grande parte dos estudantes da instituição, o tema musical escolhido não tinha qualquer apelo, ao contrário, era associado à marginalidade. Esse parece um exemplo da dificuldade que a escola tem de lidar com a diversidade do alunado, baseando-se muitas vezes em estereótipos que impedem a desejada identificação do jovem com a instituição.

Em vista dessa usual distância entre os proponentes dos projetos e os estudantes, a escola, em geral, não registra os seguintes aspectos que se notou claramente neste estudo: 
a. muito raramente os projetos abrangem a maior parte dos alunos; geralmente é sempre a mesma minoria que participa6;

b. o aluno do período diurno que não trabalha constitui o perfil majoritário do aluno participante;

c. esse perfil é reforçado pelos projetos que exigem presença em turnos diferentes daqueles das aulas regulares. Nesses casos, além de excluir os alunos que trabalham, também afastam os mais pobres e que moram mais distante, em vista do custo extra da locomoção;

d. os alunos que pretendem continuar estudos universitários podem recusar-se a participar de projetos que identificam como "perda de tempo" quanto ao preparo de que necessitam para submeter-se aos exames vestibulares.

Sobre o protagonismo juvenil, a maioria dos projetos não priorizava atividades de iniciativa dos alunos. No entanto, não se registrou qualquer reivindicação dos jovens para uma participação mais autônoma; eles não sugerem sequer os temas a ser discutidos. Supõe-se que os estudantes não estejam atentos à possibilidade de ocupar o espaço reservado a eles nas propostas oficiais para a explicitação de outras questões que também possam ser úteis para seu desenvolvimento.

\section{Processos que envolvem professores, gestores e alunos}

Projetos de iniciativa de um grupo de professores

Este tipo de projeto deveria ser o fulcro da reforma do ensino médio, conforme disposições das DCNEM. De fato, a insistência do documento na interdisciplinaridade e na contextualização, como eixos da reforma, coloca os projetos que envolvem diversas disciplinas como prioridade.

No entanto, foram muito raras as iniciativas dessa ordem registradas pelo estudo. Muito coerentemente, esses projetos interdisciplinares foram encon-

6. Em nosso estudo, houve uma exceção: na escola muito diferenciada quanto a recursos, os alunos já se apropriaram da cultura escolar referente à ativa participação discente nos diversos tipos de projetos e outras atividades pedagógicas em constante desenvolvimento na escola. 
trados de forma mais consistente nas duas escolas já qualificadas como "vitrinas" dos órgãos centrais. Sem dúvida, o fato de ambas as escolas terem construído identidades bem definidas (o que é, ao mesmo tempo, causa e conseqüência do bom trânsito político que mantêm com os órgãos oficiais), além de certa posição especial quanto a financiamento, faz dessas instituições campos naturais para o desenvolvimento dos projetos interdisciplinares, centrais na reforma. A presença de lideranças reconhecidas à frente de cada uma delas e de um grupo de professores comprometidos, constrói também a diferença em relação às demais escolas. Não obstante, a continuidade dos projetos já estava comprometida por mudanças nos cargos de gestão, pelo desgaste das relações seja pelo "desencanto" dos professores quanto a resultados mais visíveis sobre o envolvimento dos alunos e à melhoria da aprendizagem seja por disputas políticas mais intensas, e, principalmente, pela falta de integração entre os projetos e o currículo oficial.

A relação dos alunos com esses trabalhos interdisciplinares planejados e executados por seus professores varia, mas, em geral, eles preferem essas atividades às da rotina escolar. A exceção também diz respeito aos estudantes que pretendem ingressar na universidade.

Na verdade, esses alunos exigentes e interessados em aprender mais podem rejeitar a participação apenas operacional nos projetos. Ou seja, visto que, em geral, toda a concepção e coordenação das atividades fica em mãos dos docentes, a participação dos alunos pode-se restringir, muitas vezes, a um simples ativismo, sem possibilidade de aprendizagens significativas.

A ausência, em outras escolas, de propostas interdisciplinares elaboradas pelos docentes, pode ser atribuída a diversos fatores, muitos dos quais já examinados: precárias condições materiais e pedagógicas; falta de espaço e de disponibilidade, na cultura escolar e na cultura profissional, para trabalho coletivo; fraca coordenação pedagógica; formação docente insuficiente; ausência de controle do trabalho pedagógico e acomodação de interesses entre grupo gestor e professores.

Não foi observada reação dos alunos a essa ausência de integração interdisciplinar. Na verdade, os estudantes que chegam ao ensino médio estão há muitos anos mergulhados na cultura escolar segmentada em disciplinas. Além disso, a absoluta maioria desconhece as novas diretrizes curriculares e as possibilidades de protagonismo juvenil que as normas oficiais divulgam. 
Projetos de iniciativa individual de professores

que alguns professores nomeiam como "meu projeto" varia muito. Eis alguns exemplos:

- docente planeja levar seus alunos a realizar uma investigação de campo, na vizinhança da escola, para discutir os problemas sociais da região;

- professora de História faz com que os alunos representem dramaticamente episódios da História brasileira;

- professora de Português faz concurso de poesia entre os alunos;

- professor de Biologia (que também é guia turístico) leva um grupo de alunos para conhecer região serrana;

- professor de Física leva grupo de estudantes para centro cultural que exibe alguns experimentos científicos;

- em aula de Educação Artística, alunos são incentivados a reproduzir em forma de grandes painéis - obras de conhecido pintor, para decoração dos corredores da escola.

Em geral, o grupo gestor elogia muito tais iniciativas individuais dos docentes que, aparentemente, quebram a rotina da sala de aula. Esses trabalhos, por limitados que sejam, são sempre relatados como um indicador da qualidade do ensino na escola. Os professores, sujeitos dessas ações, também demonstram satisfação por ter algum trabalho diferenciado. Essa apreciação positiva indiscriminada, sem avaliação dos benefícios concretos para os alunos, parece indicar um traço marcante da cultura escolar, que valoriza um certo ativismo pedagógico sem atenção para o conteúdo e os resultados.

A reação dos alunos é também variável. Em geral, apoiam atividades fora da rotina, mas, evidentemente, nem todas os motivam. Algumas propostas individuais dos professores, como viagens e visitas a outras instituições, são apreciadas, mas criticadas por possibilitar apenas a participação de pequenos grupos, principalmente porque os custos dos deslocamentos devem, em geral, ser pagos pelos estudantes.

As oportunidades de protagonismo juvenil que esses "projetos individuais" podem proporcionar não são enfatizadas pelos alunos. Observou-se 
porém que algumas vezes, o controle da situação pedagógica passou, muito nitidamente, das mãos dos docentes para os alunos, quando, por exemplo, os estudantes transformaram em lazer o planejado conteúdo pedagógico. Isso acontece, principalmente, com viagens e visitas a outras instituições, quando o esforço do professor para relacionar as situações novas com o conteúdo de sua disciplina é ignorado pelos jovens, que procuram apenas aproveitar o espaço lúdico das visitas. Esse processo de perda de controle é motivo de queixa dos professores, mas é compreensível, quando se sabe que oportunidades de passeios e viagens são bastante remotas para grande parte dos jovens das escolas públicas.

Adicionalmente, há situações de sala de aula que os professores não chamam de projetos e que, muitas vezes, não são sequer de conhecimento do grupo gestor, mas que são altamente valorizadas pelos alunos. São situações inerentes à forma de ensinar de alguns professores que "desafiam os alunos a pensar". Há diversos registros de afirmações dos jovens sobre a validade dessa metodologia. Pode-se dizer que, sem nomear, os alunos, em tais situações, sentem-se "protagonistas" de sua aprendizagem. É a metodologia que contextualiza adequadamente os conteúdos e problematiza de forma inteligente os conceitos, de modo que os jovens se sentem desafiados e interessados, descobrindo que o conteúdo curricular pode ter significado em suas vidas. Essas oportunidades (raras) de "atividade intelectual" questionam a ênfase da reforma nos "projetos", transformados, muitas vezes, em simples "ativismo", pobre em avanços cognitivos.

\section{Outras atividades que não fazem parte da rotina da sala de aula}

Entre a variedade de atividades e propostas que as diferentes escolas definem como "projetos" há uma série de ações bastante diversas que não podem se classificadas em nenhum dos "tipos" até aqui analisados, mas que podem constituir espaços em que o protagonismo juvenil é exercido.

- Teatro

As atividades de teatro estavam, de alguma forma, presentes nas cinco escolas estudadas. Os entrevistados referiam-se a atividades de teatro como "projeto". 
Apesar das diferenças quanto a recursos, organização e estruturação, os grupos de teatro representavam, sem dúvida, importante espaço para a participação dos alunos. Em uma das escolas, os alunos assumiram, de forma mais efetiva, a oportunidade de expressão, escrevendo eles mesmos as peças, fazendo a iluminação e ensaiando com menor participação do coordenador. A limitação desses "projetos" está no fato de abrigar apenas um pequeno grupo de "jovens protagonistas", embora, evidentemente, mesmo apenas como platéia, a maioria dos alunos possa se beneficiar desse tipo de atividade.

Nas unidades estudadas, a importância do grupo de teatro era consenso entre professores, alunos e grupo gestor, sendo também citado como exemplo da qualidade da escola. Entretanto, houve dois casos em que a atividade teatral dependia de trabalho voluntário (não remunerado) de um "coordenador/diretor", professor ou pessoa da comunidade. Nenhum dos nossos interlocutores manifestou estranhamento pela falta de financiamento oficial para um "projeto" considerado essencial.

- Competições esportivas e gincanas culturais

Atividade predileta de muitos alunos, essas competições podem ser, às vezes, organizadas pelos próprios estudantes, por meio do grêmio, ou já fazer parte do calendário escolar. Quando implicaram suspensão de aulas, os pais manifestaram sua inconformidade com a situação, uma vez que os jogos e competições em geral, mesmo as culturais, não são consideradas, pelo senso comum, como componentes pedagógicos do currículo.

Professores e gestores insistiram na importância pedagógica dessas atividades, mas poucos se dispõem a um envolvimento mais profundo com elas. Registrou-se uma gincana cultural que incluía conteúdos de algumas disciplinas, mas que não motivou um trabalho coletivo dos docentes. Adicionalmente, professores e gestores também demostraram não saber lidar bem com situações em que as rivalidades se exacerbam. Houve desdobramentos bastante conflituosos dessas atividades, em que objetivos diferentes da direção, dos alunos e entre alunos foram confrontados. Sendo impossível o consenso, prevaleceu a hierarquia, mas a animosidade perdurou, prejudicando por muito tempo as relações entre a direção, alguns professores e um grande grupo de alunos.

Conclui-se que esses espaços não são considerados pelos sujeitos da trama escolar como adequados a promover a autonomia dos alunos. Sabe-se que 
essas atividades de competição - que podem ser úteis para o desenvolvimento integral dos jovens e de seu protagonismo - exigem dos gestores e professores uma habilidade pedagógico-didática muito sólida de forma a ressaltar a importância da participação e não apenas da competição. $\bigcirc$ que prevaleceu foi a ênfase, por parte dos alunos, apenas nos aspectos competitivos, levados às últimas conseqüências, com todas as seqüelas de conflitos e agressões que daí decorrem.

- Cursos especiais de preparação para a universidade

Embora os documentos oficiais da reforma tenham procurado minimizar o histórico objetivo propedêutico do ensino médio, transformando o "preparar para a universidade" em "preparar para a vida", persiste muito fortemente na cultura das escolas médias aquele prestigiado objetivo, que tradicionalmente serve de indicador da qualidade da instituição.

Algumas escolas estudadas perseguem esse objetivo de forma paralela ao currículo, montando cursos preparatórios para os exames de acesso ao ensino superior, cursos esses ministrados aos sábados por professores voluntários. O trabalho voluntário de docentes - alguns dos quais, diversas vezes, recusaram a se envolver em outros projetos curriculares - expressa bem o que significa para as escolas, em termos de prestígio social, o ingresso de seus exalunos na universidade. Não se observou autocrítica dos docentes quanto à insuficiência dos cursos regulares para preparar os alunos para a continuação dos estudos. Ao contrário, o grupo gestor e os professores referiram-se com grande satisfação aos cursos preparatórios, julgando o trabalho voluntário como uma prova da dedicação e profissionalismo do corpo docente.

Quanto aos alunos, registrou-se reação diferenciada, com base em uma avaliação muito realista de suas possibilidades de ingresso na universidade. Os jovens que, por condições familiares mais propícias, podem adiar seu ingresso no mercado de trabalho e/ou vêem possibilidades de pagar uma universidade particular, ou aqueles que sonham com a muito distante possibilidade de ingresso nas disputadíssimas universidades públicas apropriam-se com muita disposição da oportunidade extra oferecida. Os outros (a maioria) simplesmente ignoram o espaço aberto pela escola.

Foram observadas, ainda, em algumas escolas, outras formas de favorecer os candidatos à universidade, por exemplo, condições especiais para par- 
ticipar de projetos e maior acesso a recursos do estabelecimento, como computadores e biblioteca.

Além disso, em diversas oportunidades, percebeu-se um pacto não declarado entre professores e alunos considerados fortes candidatos ao ensino superior. Em primeiro lugar, esses jovens, em geral, se diferenciam daqueles que não mostram interesse (ou não vêem possibilidade) na continuação dos estudos. Consideram-se um grupo distinto e criticam os estudantes "desinteressados e bagunceiros". Essa postura pode criar certa cumplicidade entre os aspirantes à universidade e os professores que têm dificuldade de tratar com a diversidade da sala de aula, mas que gostariam de ser bem-sucedidos em seu trabalho. Tais professores também costumam classificar os estudantes como desinteressados, problemáticos, indisciplinados e interessados e disciplinados. Essa distinção coincide, diversas vezes, com a distribuição dos alunos nos turnos diurno e noturno, tendendo os jovens do diurno a ser "bons alunos" e os do noturno, "desinteressados, sempre cansados, bagunceiros". Concomitantemente, essa qualificação dos estudantes também pode coincidir com os aspirantes à universidade e aqueles inseridos (ou a se inserir) no mundo do trabalho.

Sem dúvida, contribuir para que alunos de escola pública tenham acesso à universidade pode representar um galardão para muitos docentes. Nesses casos, levanta-se a hipótese de apropriação de espaço das aulas regulares por esse tipo de aliança, o que pode excluir a maioria dos estudantes.

Trata-se aqui de microprocessos que confrontam de maneira peculiar os objetivos oficiais de tornar o ensino médio uma "escola única". Supomos ter registrado - nos casos estudados - estratégias de apropriação que apenas reproduzem a fratura existente na sociedade mais ampla, reprodução que a reforma tentou superar de forma legalista e burocrática.

\section{AVALIAÇÃO DO RENDIMENTO ESCOLAR}

A reforma curricular do ensino médio prevê que as atividades de avaliação do rendimento dos alunos sejam processuais e formativas, no sentido de abrir espaço para que todas as expressões dos alunos - e não só as canalizadas por exames e provas - sejam consideradas oportunidades de aferição de avanço de aprendizagens significativas. Para que a avaliação cumpra essa função, a participação do aluno, inclusive em processos de autoavaliação, deveria 
ser considerada. Além disso, no contexto da reforma, previu-se a possibilidade de avaliar o desenvolvimento de diversas competências adquiridas pelos estudantes, especialmente aquelas derivadas de seu envolvimento em diferentes projetos interdisciplinares.

Em São Paulo e no Ceará, os órgãos centrais estabeleceram novos sistemas de avaliação que entraram imediatamente em confronto com princípios muito sólidos, tanto da cultura escolar quanto da cultura docente.

Em São Paulo, a chamada avaliação formativa e processual no ensino médio foi legalmente regulada, pela Secretaria Estadual de Educação, mediante o sistema de "progressão parcial", pelo qual os alunos podem ser promovidos em algumas disciplinas e ficar reprovados em outras, de forma que seu processo de promoção não seja totalmente interrompido. Do ponto de vista de racionalidade pedagógica, a proposta faz todo sentido. No entanto, ela foi recebida nas escolas como uma imposição descabida. $\bigcirc$ maior argumento é o de que a escola não tem estrutura - nem física, nem organizativa - para atender alunos que deveriam acompanhar disciplinas em duas séries diferentes. Para os alunos que trabalham, também se torna impossível freqüentar a escola em períodos distintos para cumprir duas cargas horárias distribuídas em diferentes séries.

Nesse confronto, era de se prever que os professores encontrariam estratégias de apropriação da norma imposta de modo a cumprir as formalidades legais e não criar o que classificavam como "caos" organizacional-administrativo. Assim, na verdade, nas escolas estudadas, está praticamente estabelecida a promoção automática, evitando-se que os alunos fiquem retidos em algumas disciplinas.

No Ceará, embora com disposições diferentes, o novo sistema de avaliação acabou tendo as mesmas seqüelas que as descritas no caso de São Paulo. Naquele estado, a chamada avaliação formativa, processual e descritiva obteve péssima acolhida. Os docentes alegavam que dando aulas em duas ou três escolas, com um total de 500, 600 até mil alunos, a avaliação qualitativa/descritiva torna-se uma impossibilidade, uma vez que não podem conhecer os estudantes de forma mais próxima e muitas vezes não sabem sequer os seus nomes (Zibas, 2005).

Tanto em São Paulo quanto no Ceará, os alunos contatados reagiram de maneira semelhante aos novos procedimentos de avaliação: eram contra, fazendo coro às vozes dos professores, os estudantes com melhores perspecti- 
vas de continuar os estudos e aqueles que genuinamente acreditavam no valor das notas como termômetro de sua aprendizagem. Para outros (a maioria, em nossa avaliação), embora as reprovações continuassem no horizonte, os novos sistemas eram bem-vindos, por parecerem muito menos restritivos e bastante complacentes com um relaxamento da disciplina de estudos.

Um caso excepcional foi registrado: a escola que, discordando da norma oficial, acabou propondo uma forma de avaliação muito mais exigente, que combina um sistema de notas e uma avaliação qualitativo-descritiva, além de incluir espaço para que os alunos avaliem individualmente os docentes. Esse foi o único caso de proposta de avaliação de docentes por alunos, com as reações contrárias - previsíveis - de muitos docentes. Os alunos da escola reagiram com cautela à nova avaliação. Muitos expressaram preocupação com os aspectos subjetivos da avaliação descritiva, preferindo ser avaliados por notas. Estavam, sem saber, concordando com diversos especialistas (Bernstein, 1984, por exemplo) que afirmam ser muito mais evasiva e autoritária uma avaliação descritiva que não focaliza apenas um desempenho específico do aluno, mas traços de seu caráter e personalidade. Quanto à avaliação dos docentes pelos alunos, os jovens aderiram com entusiasmo à nova sistemática, e, embora cada estudante devesse avaliar individualmente cada professor, a situação favoreceu demoradas discussões entre grupos de estudantes com o objetivo de chegarem a um resultado mais justo.

Esse caso leva à reflexão sobre a generalizada ausência de propostas institucionais de avaliação dos professores pelos alunos. Em contexto no qual se tenta introduzir o protagonismo juvenil, esse tipo de atividade poderia ser um excelente instrumento de desenvolvimento dos jovens.

\section{CANAIS INSTITUCIONAIS E ORGANIZAÇÕES INFORMAIS}

\section{Conselho Escolar}

O principal canal previsto na LDB para a expressão dos interesses dos alunos é o Conselho Escolar, que deve ser instalado em todas as escolas públicas de ensino fundamental e médio, com a participação de representantes da comunidade e de todos os segmentos da escola, para garantir a democratização da gestão institucional. 
Essa formalização legal não tem impedido o conhecido funcionamento precário dos conselhos, uma vez que sua representatividade pode ser manipulada pelos dirigentes da escola e sua função deliberativa tende a se transformar em simples ratificação de decisões já tomadas pelo grupo gestor. Constituindo os alunos, historicamente, o segmento mais vulnerável do tecido escolar, pode-se supor que sua participação nos enfraquecidos conselhos seja ainda mais problemática.

Este estudo traz elementos que reforçam tal suposição. Em todos os casos analisados, a atuação dos representantes dos alunos era apenas formal ou não existia. Quando entrevistados, os estudantes expressaram constrangimento de participar de reuniões cuja agenda desconheciam, cujas discussões não entendiam e cujos rituais os intimidavam. Com esse tipo de representação discente junto ao conselho, não é de se estranhar que outros alunos entrevistados demonstrassem não saber sequer da sua existência na escola.

Nesse cenário, a procura da expressão do protagonismo do alunos tornase inútil.

\section{Grêmio}

grêmio estudantil tem uma história de algumas décadas. A partir da reforma do ensino médio, entretanto, sua instalação e funcionamento revestiram-se de nova importância, em vista da ênfase da legislação sobre o protagonismo do aluno em todas as esferas da vida escolar.

Atualmente, a obrigatoriedade da existência de grêmios nas escolas de ensino médio está instituída por lei em alguns estados, como no Ceará e em São Paulo. Essa obrigatoriedade, no entanto, nem sempre é cumprida.

Em sua origem, nos anos 60, os grêmios tinham uma participação política bastante acentuada, pois confrontavam-se com governos militares. Naquelas circunstâncias, reunidos em uma grande organização nacional - a União dos Estudantes Secundaristas do Brasil -, e impossibilitados de levantarem as grandes bandeiras contra a ditadura, usavam qualquer pretexto para manifestações fora dos muros da instituição, desde reivindicação das mais particulares (por exemplo, destituição de um diretor autoritário), até as mais gerais (como protesto pelos baixos salários dos professores e o custo dos transportes).

Com a democratização e a desmobilização dos movimentos sociais, in- 
clusive com o enfraquecimento da organização nacional dos estudantes, o papel dessas entidades estudantis perdeu importância e hoje reconhece-se, em geral, que têm uma atuação frágil e descoordenada, apesar da atual ênfase na participação efetiva dos jovens na vida da escola e da comunidade.

No entanto, mesmo nessa situação de fragilidade, é legítimo supor que os grêmios continuem a desempenhar papel considerável no jogo de poder que se desenvolve no campo institucional. Por exemplo, sua eleição pode ser "apadrinhada" pelo grupo gestor, resultando daí transformar-se em instrumento de controle do alunado e não representante de seus interesses, como em um caso observado. Um grêmio, considerado autônomo em sua constituição e atuação dentro da escola, pode também, por sua vez, tentar a manipulação dos alunos em benefício de interesses próprios ou de outras entidades fora da escola, como por exemplo, um partido político, uma associação de bairro etc. Mas, também, pode tornar-se veículo atuante do protagonismo juvenil, dentro ou fora da escola.

Em nossa pesquisa, verificou-se que os grêmios estavam estabelecidos em todas as instituições estudadas. Mas isso não é garantia de permanência. As associações de alunos apresentam descontinuidade, pois, sendo de três anos a duração do curso médio, a passagem dos alunos pela escola é rápida e nem sempre há suficiente tempo para maturação de novos grupos que se mobilizem para substituir os dirigentes gremiais, quando estes terminam o curso e deixam a escola.

A relação de professores e gestores com os grêmios mostrou-se ambígua. Em geral, estão preocupados com o cumprimento da exigência legal de instalação dessas associações. Assim, agem em diversos níveis para estimular os alunos a se organizarem, inclusive reservando uma sala para seu uso. Apesar de sua origem muitas vezes induzida, o que sugere espaço para manipulação, o grêmio, uma vez em funcionamento, pode passar a ameaçar a tranqüilidade da hierarquia escolar. A queixa de que "eles questionam muito" foi bastante ouvida pela equipe de pesquisa.

Nesse clima, até reivindicações banais podem ser tratadas como "insubordinações". Reclamações sobre o desconforto nas salas de aula por falta de cortinas, e sobre a insuficiência de bebedouros nos pátios, pedido de abertura de espaço externo, ocioso, para uso dos alunos, ou sugestão de instalação de aparelho de som para animar os recreios - todos esses pleitos foram objeto 
de intensas batalhas entre gestores e estudantes, sendo relatados pelos alunos, em casos de sucesso, como as grandes realizações de sua associação.

A ambigüidade da relação grêmio-gestores e professores fica mais clara quando a reclamação relativa à postura reivindicatória dos estudantes vem acompanhada de críticas quanto à atuação apenas "de recreação" do grêmio. Ou seja, quando a organização dos alunos mostra sua face política, o establishment escolar sente-se ameaçado e procura desmobilizá-la; quando o grêmio atende os interesses mais imediatos dos jovens, promovendo festas e outros tipos de atividade de lazer, a direção da escola percebe apenas o objetivo de faltar às aulas e fugir das obrigações escolares. Esta última crítica mostra a incompreensão da escola com respeito à característica "juvenil" dos alunos, preferindo tratá-los apenas como "estudantes". Essa redução das características dos alunos é, reconhecidamente, um dos fatores da falta de identificação entre os jovens e a escola.

Os embates entre grêmios e a direção dos estabelecimentos são muito conhecidos e diversos autores já os analisaram. Segundo Ghanem (1989, 1995), os gestores, receosos de terem suas decisões e ações educativas questionadas e de "perderem o controle do funcionamento 'normal' (e ritual) das aulas" (1995, p.64), não só evitam discutir com os jovens seus direitos e deveres, presentes nos regimentos escolares, como bloqueiam muitas vezes suas ações livres e coletivas; "sem conhecer seus direitos, os estudantes ficam submetidos a decisões arbitrárias. Suas iniciativas são tolhidas, seus movimentos são vigiados e suas propostas proibidas" (1989, p.48).

Este estudo registrou diversas situações que parecem confirmar a análise de Ghanem: tentativa de destituição de diretoria do grêmio, com o pretexto de que o rendimento escolar desses alunos estava insuficiente; proposta de tarefa que caberia a funcionário da escola, numa clara tentativa de manipular e dirigir a ação dos alunos; campanha ostensiva contra candidata à diretoria do grêmio, cujo perfil combativo ameaçava interromper uma sucessão de diretores gremiais visivelmente manipulados pelos gestores da escola.

Essas ações autoritárias aconteceram sob diferentes estilos de gestão. Mesmo em escola cujo projeto é considerado modelo para a rede estadual e na qual foi registrado um compromisso profissional e político muito claro de diversos docentes, ocorreu tentativa muito grosseira de intervenção na livre associação dos estudantes. Essa dificuldade manifesta por professores e gestores 
de aceitar uma relação democrática com as organizações estudantis parece apoiar-se em diversos fatores: a cultura escolar tradicional, que supõe a submissão dos alunos à hierarquia; a insegurança profissional dos docentes, que não estão preparados para questionamentos de sua atuação; o desconhecimento da cultura juvenil e, portanto, o preconceito quanto à possibilidade de uma ação responsável dos jovens.

Registraram-se, entretanto, situações de confronto em que a associação dos alunos acabou sobrepondo-se às demonstrações de força da hierarquia escolar. Foram observados, nesses casos, claros movimentos de apropriação, passando o controle, nesses espaços limitados e nessas situações especiais, para as mãos dos alunos organizados.

Constatou-se ainda que a posição política clara do diretor do grêmio e sua capacidade de negociação pode conferir uma dimensão diferenciada à entidade. Em um dos casos encontrou-se uma estratégia política desdobrada em três níveis. Atendendo os interesses mais imediatos do alunado, o grêmio organizava festas e outras atividades de lazer, fortalecendo, com isso, a comunicação entre grêmio e corpo discente. Ao mesmo tempo, ia ao encontro das expectativas da diretoria, promovendo a distribuição de mantimentos à vizinhança mais carente e projetando, assim, o nome da escola na comunidade. Trabalhava ainda com alunos de outras escolas, com vistas a uma organização em nível regional dos estudantes e procurava a orientação de órgão da sociedade civil voltado para a defesa dos direitos de crianças e adolescentes. Esse é um bom exemplo das possibilidades de protagonismo juvenil que o grêmio pode abrir aos estudantes, a depender do nível de discernimento político de seus componentes e das relações estabelecidas com outros segmentos organizados da sociedade.

\section{Jornal e rádio escolar}

jornal escolar pode ser outro espaço para a expressão do protagonismo juvenil. No entanto, ao contrário do grêmio, sua existência não está regulamentada por normas oficiais, dependendo, em cada caso, da dinâmica da instituição.

Em três das escolas investigadas, estava estabelecido esse canal de comunicação. Dois deles, em escolas cearenses, eram patrocinados por uma ONG 
com o objetivo específico de incentivar a criação de jornais escolares, inteiramente elaborados e administrados pelos alunos, desvinculados da administração da escola e sem qualquer interferência, quanto aos conteúdos, da organização patrocinadora. O terceiro, também no Ceará, era sustentado pela própria escola.

Foi importante estabelecer a diferença entre esses dois tipos de patrocínio; detectou-se nitidamente uma linha crítica, com temas mais amplos, nacionais e internacionais, adotada pelos jornais autônomos, ao mesmo tempo em que o jornal tutelado pelo grupo gestor tratava de temas banais, internos à escola.

Os alunos responsáveis pelos jornais independentes faziam curso de técnica jornalística e tinham reuniões periódicas de discussão com colegas de outras escolas. Eram incentivados à leitura e à participação em outros eventos culturais. Os resultados dessa exposição a outras esferas sociais foram explicitamente louvados por uma aluna, que comparou sua anterior situação de apatia social e política ("eu não queria saber de política") com seu atual nível de compreensão social.

Tende-se a concluir que a ONG tenta desempenhar, de forma sistemática e organizada, o papel que, em décadas anteriores, estava a cargo das associações de estudantes de âmbito nacional. Ou seja, a abertura de espaços de debate, de interação com outras visões de mundo, antes possibilitada pela mobilização dos jovens em nível nacional, é agora atividade específica de uma organização não governamental. $\bigcirc$ avanço social e político dos jovens associados aos objetivos da ONG pareceu evidente. Isso não obscurece a questão do estreitamento dos espaços públicos de exercício da democracia, agora, em muitos casos, tutelados pela vontade política e idiossincrasias de organizações não governamentais.

Outro canal formalizado que pode, teoricamente, transformar-se em vetor do protagonismo juvenil diz respeito ao "rádio" escolar. A reivindicação, batalhada com muito entusiasmo pelos alunos, parece referir-se apenas ao seu uso como veículo de animação dos recreios, com a divulgação de programação musical específica. Embora essa ocupação do espaço escolar possa ser importante para a expressão dos jovens, ela é limitada se não utilizada para organização dos alunos em torno de outros interesses. Entretanto, as condições de funcionamento desse canal de comunicação, em meio ao ambiente tumultua- 
do e barulhento dos recreios, sujeito à interferência do grupo gestor para veicular avisos ou exortações de diversos tipos, parece estreitar as possibilidades desse instrumento.

\section{Atuação juvenil à margem dos canais institucionais}

A organização espontânea dos jovens - à margem da intermediação dos canais institucionalizados, como grêmio, Conselho Escolar, jornal etc. - tornase inevitável em algumas circunstâncias do cotidiano. Quando as condições de ensino chegaram a um nível insuportável, foram registrados protestos intensos e generalizados dos alunos, sem qualquer convocação específica de seu órgão representativo. Um exemplo foi a indignação geral causada pela falta de professores de algumas disciplinas, irregularidade que, em diversos casos, podese prolongar por alguns meses e que os órgãos centrais não têm conseguido superar, tanto em São Paulo, quanto no Ceará. Essa situação de encolhimento do magistério, ou falta de candidatos às funções docentes, é explicada muitas vezes pelas difíceis condições de trabalho e baixos salários.

Em outras ocasiões, as diferenças de objetivos entre alunos, grupo gestor e professores se exacerbam. Essas situações, geradas, principalmente, pela falta de flexibilidade da hierarquia escolar e pelo não-reconhecimento, por parte dos alunos, da representatividade do grêmio, podem extrapolar os muros escolares, levando a contenda até os órgãos intermediários da administração. Em algumas oportunidades, foram constatados enfrentamentos radicalizados, em que os jovens também mostraram saber empenhar-se por aquilo que julgam ser seus direitos.

Essas explosões esporádicas da expressão dos interesses juvenis não retratam, evidentemente, toda a rede de relações entre jovens - rede mais ou menos visível, dependendo de cada caso -, em que grupos se formam em torno de afinidades diversas ou se contrapõem a respeito dos mais variados temas. Essa "cultura subterrânea", raras vezes percebida, foi analisada por Ezpeleta e Rockwell ( 1 985) junto a crianças menores. Com relação aos adolescentes, em geral se supõe que essa trama submersa seja mais complexa, formada com base em expressões de solidariedade e cumplicidade de difícil leitura para os adultos. São, sem dúvida, estratégias de sobrevivência em meio a exigências dos professores e regras institucionais nem sempre compreensíveis e muitas ve- 
zes situadas além da possibilidade de serem cumpridas. Alguns indícios dessa rede aparecem quando alunos recém-chegados já enfrentam a sala de aula com uma avaliação de seus novos professores: "aquele é durão, não admite brincadeiras"; "o outro a gente pode enrolar e ele dá nota do mesmo jeito" etc. Outra face dessa solidariedade juvenil pode realizar-se para encobrir afrontas mais sérias às normas escolares e sociais, como o consumo de drogas. Enfim, são significados do cotidiano que vão sendo construídos e reconstruídos em um incessante movimento de apropriação/construção da cultura escolar.

\section{ORGANIZAÇÃO E USO DO ESPAÇO FÍSICO}

Os educadores aprenderam com Foucault $(1978,2003)$ que não é possível minimizar a importância da arquitetura escolar e da disposição e organização do espaço físico para o desenvolvimento dos processos de ensino-aprendizagem. No caso desta pesquisa, sobre o protagonismo dos alunos, a atenção a tais características da materialidade da instituição se tornam essenciais. Em geral, concorda-se que uma arquitetura escolar, que limita os movimentos dos alunos, impede também a comunicação entre eles e outros agentes do cotidiano escolar, e oferece aos professores um lugar proeminente do qual possam dominar a situação e ser o centro de atenção, exprime e/ou favorece uma pedagogia repressora, em que pesem os discursos libertários que possam circular por tais espaços.

Nas escolas, tanto em São Paulo quanto no Ceará, diversas vezes foi registrada a profusão de grades, portas trancadas e portões fechados e vigiados que cerceiam a liberdade de circulação dos alunos. Essa característica das construções escolares é, em geral, justificada pelos altos índices de violência urbana registrada no país.

É fato comum, em todas as escolas, que as dependências que guardem algum equipamento de valor - como laboratórios de ciências e informática e bibliotecas - quando não em uso, permaneçam trancadas. Principalmente nas duas escolas paulistas estudadas, a característica "gradeada" dos estabelecimentos chega a causar impacto ao visitante, mesmo aquele já bem acostumado a essa características de todas as construções das grandes cidades brasileiras.

Observaram-se algumas situações de segregação dos alunos muito reveladoras de relações intramuros não facilmente explicitadas. Em dois casos, 
os pátios de recreio eram totalmente isolados. Ao deixar as salas de aula para o período de descanso, os alunos eram literalmente confinados em um espaço interno cujas saídas eram bloqueadas. Uma vez no recreio, os jovens estavam impedidos de voltar às salas de aula ou circular em qualquer outro espaço, pois também estavam bloqueados os acessos a salas dos professores, biblioteca e direção. Em uma das escolas, a sala do diretor ficava sempre totalmente inacessível aos alunos, atrás de duas portas, sendo uma gradeada e guarnecida de corrente e cadeado.

Tal organização dos espaços obriga a todos do grupo gestor e auxiliares a andarem com grandes molhos de chave. Nesse contexto, os franqueadores dos portões e os portadores das chaves ganham muita importância na dinâmica escolar, pois muitas vezes qualquer fluxo de pessoas - e não só de alunos - é interrompido por não estarem disponíveis esses guardiães da circulação interna.

Nas escolas cearenses, embora o sistema de grades estivesse implantado, este era bem menos agressivo, seja pelo menor número de obstáculos, seja porque os espaços para recreio eram bem maiores, com uma parte ao ar livre e arborizada. Nessas escolas, o acesso à direção, secretaria e biblioteca estava sempre franqueado aos jovens.

Note-se que os gestores das escolas "mais gradeadas" mostraram-se entusiastas da pedagogia que favorece o protagonismo dos alunos, insistindo com professores para que suas aulas fossem planejadas de forma a sair da rotina e privilegiar a participação, a iniciativa dos jovens. $\bigcirc$ paradoxo entre essa disposição pedagógica e a materialidade da escola, expressa por sua arquitetura e organização dos espaços físicos, não era percebido por esses educadores.

\section{CONSIDERAÇÕES FINAIS}

Na conclusão da análise sobre os microprocessos escolares, parece necessário reafirmar que partimos do pressuposto de que as instituições escolares não são independentes das estruturas básicas da sociedade, exigindo sempre, para melhor compreensão do processo educacional, a abordagem da articulação entre a micro e a macropolítica, ou entre a escola e os condicionantes mais amplos. No entanto, para estudar aquelas instituições, em um primeiro nível, como organizações de relativa autonomia que também são, a análise da micropolítica escolar mostrou-se adequada. 
O resultado do estudo constitui um painel multivariado - mas bastante inteligível - das relações que se estabelecem e se alteram constantemente no dia-a-dia das cinco escolas estudadas, principalmente quando tais relações são confrontadas com novas normas pedagógicas ou de gestão.

Consensos, conflitos, dissimulações e omissões registrados parecem confirmar que a pretensão de impor diretrizes centralizadoras, sem consideração dos processos internos de releitura ou ressignificação, enfraquece, já a priori, qualquer iniciativa oficial. Nas escolas estudadas, o protagonismo juvenil, tal qual proposto por órgãos centrais, tinha pouca penetração. Essa circunstância pode ser explicada, em parte, pelo desconhecimento que os profissionais entrevistados demonstraram a respeito das diretrizes oficiais. Por outro lado, parece válido, à luz do exposto, levantar a hipótese de que a superficialidade com que o tema foi tratado nas escolas deve-se, também, à ausência ou, pelo menos, à compreensão apenas parcial do significado do termo, no mais das vezes confundido com participação formal ou com ativismo, sem desafio intelectual mais efetivo e/ou sem possibilidade de compromisso com a ação coletiva. As situações relatadas sugerem que as tentativas apressadas de tornar didáticos ou operacionais conceitos presentes nos documentos da reforma acabam por produzir distorções que dificultam a compreensão crítica deles, por sua naturalização e transformação em recomendações simplificadas sobre o caminho a ser trilhado. Apesar disso, as dinâmicas freqüentemente conflitivas do cotidiano, às vezes permeadas pela retórica oficial sobre a importância do protagonismo juvenil, acabam criando algumas oportunidades para a construção da autonomia dos alunos.

\section{REFERÊNCIAS BIBLIOGRÁFICAS}

BALL, S. J. La Micropolitica de la escuela. Madrid: Paidós; MEC, 1989.

BRASIL. Ministério da Educação e Cultura. Diretrizes Curriculares Nacionais para o Ensino Médio. Braślia: CNE, 1998.

BERSNTEIN, B. Classes e pedagogia. Cadernos de Pesquisa, São Paulo, n.49, p.26-42, maio 1984.

EZPELETA, J.; ROCKWELL, E. Escuela y clases subalternas. In: IBARROLA, M.; ROCKWELL, E. (orgs.) Educación y clases populares em América Latina. Mexico: DIE, 1985. p. 195-215. 
FOUCAULT, M. Microfísica do poder. São Paulo: Graal, 2003.

Vigilar y castigar. Madrid: Siglo XXI, 1978.

GHANEM, E. Os Grêmios livres e o movimento secundarista. Cadernos do CED/, São Paulo, n. 19, p.35-5I, jan. 1989.

. Papel do grêmio estudantil e a qualidade do ensino no curso noturno. Idéias, São Paulo: FDE, n.25, p.61-70, 1995.

HERAS MONTOYA, L. Compreender el espacio educativo. Granada: Aljibe, 1997.

RIBEIRO, V. M. M. Ensino médio: novas realidades, novas propostas e novos impasses. São Paulo, s.d. (mimeo)

STAKE, R. Investigación con estudio de casos. 2. ed. Madrid: Morata, 1999.

ZIBAS, D. M. L. A Reforma do ensino médio no Ceará e suas contradições. Cadernos de Pesquisa, São Paulo, v. 35, n. I24, p.201-226, jan./abr.2005.

ZIBAS, D. M. L.; FERRETTI, C. J.; TARTUCE, G. L. B. P. A Gestão escolar como cenário de inovação educativa: o protagonismo de alunos e pais no ensino médio; cinco estudos de caso. São Paulo 2004. (mimeo) [Relatório final do Projeto OEl/FCC]

Protagonismo juvenil na literatura especializada e na reforma do ensino médio. Cadernos de Pesquisa, São Paulo, v. 34, n. I22, p.4I I-423, maio/ago.2004a.

Recebido em: setembro 2005

Aprovado para publicação em: dezembro 2005 